\title{
Caerulein Antagonism by Benzodiazepines in the Food Intake in Mice
}

\author{
Kazuhiko KUBOTA, Kiminobu SUGAYA, Ikuko MATSUDA, \\ Yutaka MATSUOKA and Masahiro ITONAGA \\ Department of Pharmacology. Faculty of Pharmaceutical Sciences, \\ Science University of Tokyo. Shinjuku-ku, Tokyo 162, Japan
}

Accepted July 8.1985

\begin{abstract}
Intracisternal administration of caerulein inhibited the food intake in mice, but the caerulein action was antagonized by benzodiazepines such as chlordiazepoxide, diazepam and flurazepam which were administered intraperitoneally in low doses $(0.2$ to $2 \mathrm{mg} / \mathrm{kg})$. The antagonism mechanism between caerulein and benzodiazepines remains unclear, but the characteristics of the antagonism were similar to those which had been observed with cholecystokinin and benzodiazepines.
\end{abstract}

Previously, authors evidenced that antinociceptive (1), hypothermic (2) and satiety (3) actions of C-terminal cholecystokinin octapeptide (CCK8) administered intracisternally to mice could be antagonized by benzodiazepines like diazepam when administered intraperitoneally in very low doses $(0.5$ to $5 \mathrm{mg} / \mathrm{kg})$. Caerulein is a decapeptide closely related to CCK8 in the sense that it has a molecular structure similar to CCK8 and possesses substantially the same pharmacological properties. Therefore. caerulein actions are also expected to be antagonized by benzodiazepines as well.

For a week before the experiment, male ddY strain mice weighing 18 to $20 \mathrm{~g}$ were housed in a controlled, air-conditioned room at $24 \pm 1{ }^{\circ} \mathrm{C}$ with a relative humidity of $55 \pm 5 \%$. During this period, the mice were fed on liquid food having the following composition (\%): protein, 7.0: fat, 7.7: lactose, 10.2: water, 73.5; ash, 1.6 (Calories: $130 \mathrm{Cal}$ $100 \mathrm{~g}$ ). Caerulein was dissolved in a vehicle, $0.4 \%$ brilliant blue aqueous solution. Ten $\| 1$ of the caerulein solution containing $50 \mathrm{ng}$ of caerulein was injected into the cerebellomedullary cistern of mice using a $J$-shaped stainless steel needle according to the method of Ueda et al. (4) $10 \mathrm{~min}$ before measurement of the food intake. Chlordiaze- poxide hydrochloride (CDP) and flurazepam hydrochloride (FZP) were dissolved in a physiological saline solution. Diazepam (DZP) was suspended in the physiological saline solution with an addition of Tween 80 at a concentration of $0.5 \%$. Benzodiazepines were injected intraperitoneally $20 \mathrm{~min}$ before the intracisternal injection of caerulein. Mice which showed abnormal behaviors like turning after the intracisternal injection were not used. Mice were fasted for $24 \mathrm{hr}$ and then allowed to have the liquid food which was kept in a $10 \mathrm{ml}$ glass pipette. The number of mice in each group was 8 . In order to confirm proper intracisternal injection, every mouse was killed after the experiment and observed for the proper spread of brilliant blue in the brain. Caerulein was purchased from Sigma Chemical Co., Ltd. CDP and DZP were offered by Yamanouchi Pharmaceutical Co., Ltd. and FZP by Nippon Roche K.K.

The cumulated food intake curve of the control mice reached a plateau about $40 \mathrm{~min}$ after the initiation of feeding. Intracisternal administration of vehicle exerted no appreciable effects on the behavior of the mice. Intracisternally administered caerulein suppressed the food intake in mice in a dosedependent manner, and $50 \mathrm{ng}$ of caerulein 
caused marked suppression of the food intake. Higher doses of caerulein produced prolonged suppression in food intake. The dose of caerulein required for suppressing the food intake by $50 \%$ was estimated to be $10.8 \mathrm{ng} /$ mouse, which was obtained on the basis of the cumulated food intake in the initial $20 \mathrm{~min}$ period (Fig. 1).

The food intake of mice which received intracisternal administration of caerulein and the effects of benzodiazepines on the caerulein action on the food intakes of mice are shown in Table 1. The food intakes in the

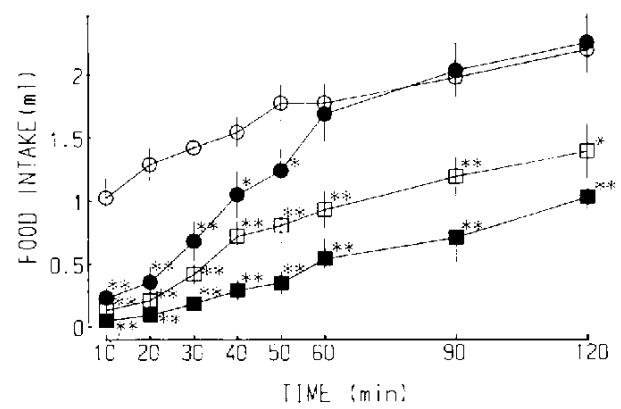

Fig. 1. Suppression of food intake by caerulein in mice. Caerulein was dissolved in a vehicle. $0.4 \%$ brilliant blue aqueous solution, and administered intracisternally. Vehicle (O), $50 \mathrm{ng}$ caerulein (O) $100 \mathrm{ng}$ caerulein ( $\square$ ), $200 \mathrm{ng}$ caerulein

Abscissa, time after the initiation of feeding: ordinate. cumulated volume $(\mathrm{ml})$ of liquid food taken by mice. Vertical bars represent the S.E. of the mean $(n=8)$. ${ }^{*} \mathrm{P}<0.01,{ }^{*} \mathrm{P}<0.05$, significant difference from the control by Student's t-test. table were obtained as the cumulated volumes of liquid food taken by mice in the $20 \mathrm{~min}$ period after the initiation of feeding. Both DZP and FZP revealed a stronger action than CDP in the inhibition of the caerulein action on the food intake of mice. Intraperitoneally administered CDP at doses ranging from 0.5 to $2 \mathrm{mg} / \mathrm{kg}$ did not appreciably affect the behavior and food intake of mice. These doses of CDP, however dose-dependently inhibited the caerulein action on mouse food intake, and a significant effect was noted with $2 \mathrm{mg} / \mathrm{kg}$ of CDP.

In the present experiment, it was demonstrated that intracisternally administered caerulein produced a more potent satiety effect in mice than CCK8 (3) and that benzodiazepines which were intraperitoneally administered in very small doses could clearly antagonize the caerulein satiety action. The anticaerulein activity of the benzodiazepines on satiety was quite similar to the anticholecystokinin activity of the benzodiazepines (3). The fact that benzodiazepines are a specific receptor antagonist of cholecystokinin (CCK) on the contraction of the gallbladder muscle has been reported previously $(5,6)$. Since caerulein has been well known to exert pharmacological effects (7-9) very similar to those of CCK, it is very likely that it will also act on the CCK receptor. Therefore, it is possible that the anticaerulein action of benzodiazepines on satiety may be

Table 1. Cumulated food intakes in mice that received intracisternal (i.cist.) administration of vehicle or caerulein and intraperitoneal (i.p.) administration of saline or benzodiazepines

\begin{tabular}{|c|c|c|c|}
\hline Drug & i.p. dose $(\mathrm{mg} / \mathrm{kg})$ & $\begin{array}{l}\text { Vehicie (i.cist.) } \\
\text { meantS.E. (ml) }\end{array}$ & $\begin{array}{l}\text { Caerulein (i.cist.) } \\
\text { mean } \pm S . E .(\mathrm{ml})\end{array}$ \\
\hline Saline & & $1.14 \pm 0.10$ & $0.36 \pm 0.12^{u}$ \\
\hline \multirow[t]{3}{*}{ CDP } & 0.5 & $1.12 \pm 0.14$ & $0.38 \pm 0.12$ \\
\hline & 1.0 & $1.22 \pm 0.19$ & $0.58 \pm 0.22$ \\
\hline & 2.0 & $1.25 \pm 0.22$ & $0.88 \pm 0.13^{\mathrm{b}}$ \\
\hline Saline & & $1.24 \pm 0.11$ & $0.26 \pm 0.07$ \\
\hline $\mathrm{DZP}$ & 0.2 & $1.15 \pm 0.25$ & $0.80 \pm 0.09$ \\
\hline Saline & & $1.18 \pm 0.09$ & $0.26 \pm 0.07$ \\
\hline$F Z P$ & 0.5 & $0.99 \pm 0.11$ & $0.67 \pm 0.17^{b}$ \\
\hline
\end{tabular}

Each value represents the mean \pm S.E. $(n=8)$. "Significantly different from the group that received saline and vehicle at $P<0.01$. besignificantly different from the group that received saline and caerulein at $P<0.05$ and $P<0.01$, respectively. 
associated with the competitive antagonism between caerulein and benzodiazepines as observed in the gallbladder with CCK8 and benzodiazepines. However, in the present experiment, the concentration of benzo diazepines in the mouse brain seemed much lower than that ( 1 to 10 hM) required for antagonizing CCK8 action in the gallbladder. Thus, the exact mechanism of the berzodiazepines as antagonists of caerulein action remains unclear and its elucidation must await further investigation.

Acknowledgments: Authors wish to thank Nippon Roche K.K. and Yamanouchi Pharmaceutical Co. Ltd. for kindly supplying tho benzodiazepines.

\section{References}

1 Kubota, K., Sugaya, K., Matsuda, I., Matsuoka Y. and Terawaki, Y.: Reversal of antinociceptive effect of cholecystokinin by benzodiaze , nes and a benzodiazepine antagonist, Ro 15-1788. Japan. J. Pharmacol. 37, 101-105 (1985)

2 Sugaya, K., Matsuda, I., Sunagane, N., Matsuoka, Y., Uruno, T. and Kubota, K.: Studies on the antagonism between cholecystokinin and benzodiazepines $1 \mathrm{~V}, 104$ th. Annual Congress of Pharmaceutical Society of Japan. Abstracts, p. 504 (1984)

3 Kubota, K., Matsuda, I., Sugaya, K. and Uruno. $\mathrm{T}$.: Cholecystokinin antagonism by benzodiaze- pines in the food intake in mice. Physiol. Behav. (in press) (1985)

4 Ueda, H., Amano, H., Shiomi, H. and Takagi, H.: Comparison of the analgesic effects of various opioid peptides by a newly devised intracisternal injection technique in conscious mice. Eur. J Pharmacol. 56, 265-268 (1979)

5 Kubota, K., Sunagane, N., Sugaya, K., Uruno, T. and Matsuoka, Y.: Cholecystokinin antagcnism by benzodiazepines in the contractile resconse of the isolated guinea-pig gallb'adder. Japan. J. Pharmaco!. 33, Suppl. 87P (1983)

6 Kubota, K., Sugaya, K., Sunagane, N., Matsuda, I. and Uruno, T.: Cholecystokinin antagonism by benzodiazepines in the contractile resoonse of the isolated guinea-pig gallbladder. Eur. J. Pharmacol. 110, 225-231 (1985)

7 Zetler, G.: Analgesia and ptosis caused by caerulein and cholecystokinin octapeptide (CCK-8). Neuropharmacology 19, 415-422 (1980)

8 Itoh, S., Katsuura, G. and Maeda, Y.: Caerulein and cholecystokinin suppress $\beta$-endorphininduced analgosia in the rat. Eur. J. Pharmaco:. $80,421-425$ (1982)

9 Zetler, G.: Ceruletide, ceruletide analogues and cholecystokinin octapeptide (CCK-8): Effects on isolated intestinal preparations and gallbladders of guinea pigs and mice. Peptides 5, 729-736 (1984) 